\title{
Cooperativismo E DESENVOLVIMENTO COMUNITÁRIO
}

\author{
Erneldo Schallenberger \\ Professor Adjunto de \\ Ciências Humanas e Sociais da UNIOESTE \\ E-mail: erneldo@uol.com.br
}

Resumo

O presente artigo recorre às práticas associativas, com ênfase no cooperativismo, para apreender as suas incidências sobre as comunidades, sobre o desenvolvimento local e a sua contribuição para o processo de inovação tecnológica no universo da produção agrícola.

Palavras-chave: associativismo; desenvolvimento local; inovação tecnológica.

conceito de desenvolvimento aponta para o horizonte do futuro. Sugere a idéia de processo, de algo em movimento e em construção. Numa perspectiva mais simplificada, o conceito de desenvolvimento pode ser associado ao sentido econômico de processo contínuo de crescimento, acompanhado de indicadores econômicos e sociais em relação ao bem-estar da população (MARTINS; MARTINS, 2001). A vertente mais expressiva desta tendência criou corpo na década de 1950, quando a idéia de desenvolvimento passou a ser relacionada à de mudança social e mental, enquanto direcionada para o crescimento econômico (PERROUX, 1962).

Contemporaneamente, a forte afirmação da ideologia da globalização e o futuro incerto da sociedade sugere uma concepção 
inter e transdisciplinar do conceito de desenvolvimento, que tenha, também, implicações sobre a necessidade de apreender nas diferentes organizações sociais a inteligência coletiva e os vínculos de solidariedade ativa que impulsionam os diferentes processos de desenvolvimento local e comunitário. Evoca, portanto, princípios axiomáticos que colocam a pessoa humana no centro do processo e está associado às diferentes organizações sociais, que, ao se apropriarem de espaços locais e/ou regionais, interagem com o meio, num processo constitutivo do seu próprio modo-de-ser. O desenvolvimento é, pois, um processo coletivo de mudança social, verificado em elementos socioculturais, políticos e econômicos territorializados. O local e o regional são categorias que situam o homem no seu entorno e despertam nele a consciência da materialidade social. Por outro lado, a cultura local e/ou regional traz no seu seio o dinamismo do desenvolvimento, uma vez que é portadora das representações e do imaginário possível do uso e das decisões dos recursos sociais e naturais. O modo de vida e o progresso das comunidades são, nesse sentido, referências matriciais para a concepção de desenvolvimento.

O cooperativismo emergente como forma autônoma de organização social, concebido como uma associação de pessoas que se organizam para a satisfação das necessidades de cada um à medida que os objetivos e as necessidades de todos são alcançados, é apresentado como a via alternativa, eficiente e democrática, de uma construção social graças a qual o individual e o comunitário se fundem no horizonte da eqüidade e da justiça social. Nestes termos, o social catolicismo, veiculado pela Igreja da Imigração, tornou-se expressão concreta de vida associativa e instrumento de modelação social, de promoção das mudanças sociais desejadas e de construção dos espaços sociais comunitários no Sul do Brasil.

\section{Um primeiro entendimento acerca do conceito e da emergência do cooperativismo}

A origem do cooperativismo está associada ao processo de transformação da sociedade a partir da revolução industrial e sua com- 
preensão deve ser relacionada com os estatutos sociais do liberalismo, do socialismo e do social catolicismo. Estes estatutos expressam, com base nos referenciais que lhes são próprios, a mobilização da sociedade em torno da organização de associações que representaram a defesa, a promoção, ou mesmo a superação, dos interesses e das aspirações de grupos e/ou de classes.

O cooperativismo pode ser conceituado como doutrina econômica que sustenta a associação livre e autônoma de pessoas, que se organizam em volta de um interesse comum, para promover solidariamente a realização de suas aspirações e a satisfação das necessidades de cada um, à medida que os objetivos e as necessidades de todos vão sendo alcançados. É um sistema de organização socioeconômica fundamentado nos princípios da adesão livre e voluntária, da gestão democrática e solidária, da participação responsável, da limitação de quotas-partes do capital de cada associado, da distribuição eqüitativa dos resultados, da honestidade e da confiabilidade, da transparência e da ajuda mútua.

Pensadores como Robert Owen (1772-1858), Charles Fourier (1772-1837) projetaram novas formas de organização da sociedade, voltadas para a cooperação e para a solidariedade. Ensaios de cooperação como os de P.C. Plockboy e John Bells, que organizaram os trabalhadores para reduzir despesas e eliminar o lucro de terceiros, ou os dos 28 tecelões de Rochdale, que, animados pelos ideais socialistas, constituíram, em 1844, na Inglaterra, um capital social e fundaram uma cooperativa, foram desenvolvidos nos séculos XVII e XIX. Fernando de Lassalle, na tentativa de equacionar a questão social, havia proposto a alternativa de um socialismo cooperativo, com a criação de associações produtivas, que, vinculadas ao Estado, garantiriam uma certa estabilidade social, através de um salário - "lei do bronze". Marx criticou esta proposta, alegando que ela consagraria a miséria do proletariado, já que não previa a possibilidade da mudança social. A mudança social fundamentava-se, conforme a perspectiva marxista, na certeza de uma lei natural que promoveria a revolução social através da luta de classes e pela instituição de uma ordem social igualitária. O socialismo criou expressão política e social com a fundação do primeiro partido políti- 
co, na Alemanha, e da Primeira Internacional dos Trabalhadores, na França, na década de 1860 .

O acelerado processo de industrialização na Europa do século XIX e a desenfreada concentração de capital promoveram um quadro de exclusão social e um clima de instabilidade institucional. Para organizar os setores excluídos da sociedade e não deixá-los expostos à proposta do socialismo, pensadores do social catolicismo alemão, como Emmanuel G. Ketteler, Franz Hitze, os irmãos August e Peter Reichensperger e o pastor evangélico luterano Friedrich Naumann, fomentaram o associativismo e formularam a teoria social cristã, inspirada nos princípios da solidariedade e da cooperação, que se tornaria referência matricial para a doutrina social da Igreja, expressa na encíclica papal Rerum Novarum, promulgada por Leão XIII, em 1891. A encíclica constituiu-se em um novo estatuto social (SCHALLENBERGER, 2001).

O cooperativismo, concebido nos termos do associativismo cristão, emergiu do princípio da solidariedade cristã, numa época de profunda crise social, e foi concebido como um meio através do qual certas funções sociais poderiam ser levadas a cabo com maior eficiência, para melhor atender as necessidades de cada um e de todos. O sentido do pertencimento, segundo qual cada associado tornava-se um co-proprietário, um co-gestor e um beneficiário dos resultados, representava, de certa forma, uma possibilidade de libertação das relações de dominação pela afirmação das de cooperação. Foi uma proposta clara para fazer frente ao socialismo, diferenciada no seu conteúdo pela preservação da propriedade, com fim social, e pela busca do resultado e do lucro, visando a satisfação coletiva sem abandonar a individual. No cooperativismo, os bens individuais não são abandonados, mas dispostos enquanto possibilidade de otimização deles mesmos e de qualificação da vida privada e social. Parte da premissa de que "todo o homem que procura ajuda também deve estar disposto a socorrer os outros na necessidade". Além do mais, a organização do trabalho e dos homens em torno da produção requeria, na perspectiva do pensamento social cristão, uma ação pedagógica que aproximasse o povo das instituições sociais e que afirmasse "os princípios do cristianismo como suficientemente grandes 
para que os homens pudessem conviver e se amar" (SCHALLENBERGER, 2001, p.18). Nesse sentido, ensaiou a aproximação dos empregados aos patrões nas fábricas e dos camponeses entre si, na tentativa de construir relações de cooperação para fazer frente aos problemas da fome, do desemprego e das doenças.

O cooperativismo tomou a forma de corpo doutrinário com a fundação da Escola de Nimes, na França, em 1886. Seu maior expoente, o professor Charles Gide, prognosticava a união dos consumidores em cooperativas que acabariam por absorver todas as atividades econômicas em três etapas sucessivas: as cooperativas de consumo, que centralizariam a venda dos produtos; as cooperativas de produção, que fabricariam os produtos para as de consumo; e as cooperativas de exploração agrícola, que forneceriam a matéria-prima para as de produção (BENATO, 1994).

Na vertente alemã, Friedrich W. Raiffeisen entendia que o princípio da satisfação das necessidades repousava sobre a questão do crédito: "se cada um depositar pequenas sobras dos frutos do seu trabalho, por menores que sejam, na soma grandes projetos podem ser financiados e que podem reverter em benefício de cada um e de todos" (SCHALLENBERGER, 2001, p.18). O depósito, a formação de poupança e os empréstimos nas necessidades formariam as bases de um sistema solidário de cooperação e de ajuda mútua. Nesta perspectiva, fomentou, na segunda metade do século XIX, o desenvolvimento de Caixas de Depósito e de Empréstimo.

No Brasil, o cooperativismo criou expressão com a imigração européia, no alvorecer do século XX. Experiências como a desenvolvida pela Igreja missionária com os guaranis, nos séculos XVII e XVIII, reduzindo-os em povoados, servem de recorrência para a discussão do cooperativismo (SCHALLENBERGER, 1997). A Colônia Tereza Cristina (1847), no Paraná, é por vezes referida como modelo de organização social solidária e sustentada pelas relações de cooperação.

No Sul do Brasil, a Igreja da Imigração, tanto a católica quanto a de confissão evangélica luterana buscou legitimar o seu campo religioso pela organização de comunidades, promovendo o seu bem-estar material e espiritual. Sob a luz da doutrina social cristã, fomentou o associativismo nas suas mais variadas formas. 


\section{Imigração, associativismo e organização comunitária}

O cooperativismo brasileiro tem sua origem fortemente vinculada ao associativismo cristão, fomentado pelo social catolicismo. O associativismo cristão teve significativa receptividade entre os imigrantes europeus, sobretudo alemães e italianos. Seu surgimento está intimamente ligado a uma afirmação das necessidades sociais das comunidades étnicas do Sul do Brasil e, por isso, adquire significado quando relacionado a um tempo e local específicos. Entre as experiências vivenciadas e a imaginação futura, o imigrante articulava-se num universo de possibilidades e de limites que, em circunstâncias próprias, requeriam a superação de situações que nem sempre encontravam explicação nos referenciais legados pela tradição. As contradições internas que marcaram o processo de colonização do Sul do Brasil, são, muitas vezes, ofuscadas pela historiografia que carrega o estereótipo do pioneirismo ou posições entremeadas de conceitos que retratam o êxito da integração das fronteiras agrícolas na formação capitalista brasileira. Não interessa para 0 estudo da história do cooperativismo a disjunção entre memória e história. A construção identidária teve, certamente, nos valores internalizados da cultura e nos desafios do cotidiano a força de expressão maior para a constituição de entidades que pudessem dar respostas às reais necessidades e às utopias dos colonos. As associações, ou comunidades cívicas, representavam o espaço coletivo onde as individualidades se reconheciam no todo. As associações tornaram-se, na expressão de Siegfrid Kniest ${ }^{1}$., guardiães da colônia, mantendo viva a cultura étnica, zelando pelo reconhecimento dos valores religiosos, promovendo a educação e buscando dar guarida aos anseios dos colonos

As motivações em torno da recriação de um espaço sociocultural, portador de elementos da tradição cultural e, ao mesmo tempo, da utopia social, encontrou limites nas condições concretas de vida dos colonos, que, em ambiente diverso do da origem, tiveram que adaptar formas de produção da vida e recriar identidades.

Conduzidos para as áreas das florestas, cercados pelo latifúndio, e abandonados a sua própria sorte, tiveram que domesticar o ambi-

' Informações retiradas de Deutsches Volksblatt, 3 dez. 1924. 
ente, delimitar glebas, enfrentando, em situações variadas, problemas de posse da propriedade, de escoamento da produção e de acesso a recursos que pudessem facilitar as suas atividades. Nesse ambiente nasceram as pequenas comunidades, consagradas pela historiografia regional como colônias, que se constituíram em organizações sociais de funções múltiplas, onde a Igreja e a escola representavam os espaços públicos de legitimação e de recriação identitária e o pequeno comércio e as manufaturarias cumpriam as funções de complementaridade da produção familiar. Reduzido ao espaço doméstico, o agricultor encontrava na escola, na Igreja, no comércio e nas oficinas elementos de transcendência dos limites do mundo privado, identificando, assim, um locus público de recriação de referenciais para a construção de identidade.

A Igreja da Imigração, atenta aos vazios da colonização, tratou de mediar a organização do espaço público, tornando-se portadora de um discurso identitário e valendo-se para tal dos instrumentos da religião e da língua. Tratou, tão logo, de associar o espaço público à formação de comunidades religiosas, constituídas sobre os pilares das escolas paroquiais e das igrejas, que, além das funções da recriação cultural e do culto, dinamizaram a vida associativa.

As paróquias desempenharam um papel central na dinamização da vivência social. A partir delas nasceram as Associações Paroquiais (1890), que, na vertente católica, passaram a promover os Congressos Católicos Katholikentage -, a partir de 1898. Esses Congressos, além de reunir os alemães católicos, revigoraram a sua fé, avivaram a cultura étnica, fomentaram o associativismo e incentivaram a formação de lideranças.

As lideranças do catolicismo social assumiram funções de fronteira, visto que definiram as diretrizes da construção sociocultural em curso e tornaram-se os principais propagadores do capital religioso e cultural. Os professores paroquiais formam formados na pedagogia inaciana, o que vale dizer que os jesuítas exerceram liderança intelectual na vertente católica da Igreja da Imigração e cumpriram funções sociais modelares na vida comunitária pela articulação dos conteúdos da fé com os elementos da cultura, dando-lhes significado no cotidiano dos colonos, como muito bem o demonstrou Kreutz (1991).

A formação dos professores, católicos e evangélicos luteranos, teve como referência basilar os princípios da religião cristã e os funda- 
mentos da língua e da cultura étnica. A comunicação destes princípios e destes fundamentos dava-se pela oralidade, pelo canto e pela escrita, instrumentos mais aptos e próximos para o reconhecimento e para a recriação da identidade coletiva.

As paróquias representavam estruturas eclesiásticas com vínculos colaterais de poder e buscavam, na articulação com as comunidades, uma rede de alianças com os poderes locais para tecer relações capazes de fazer circular o seu poder religioso e moral e para introduzir as mudanças sociais desejadas ou assegurar relações estabelecidas. $\mathrm{O}$ poder local passou a ser expressão das diferentes formas de interação e participação na organização e vivência comunitárias. Diferente da base tradicional do poder local no Brasil, sustentado pelo coronelismo, o das comunidades resultava da integração de pessoas para a solução dos seus problemas, abrindo para o cidadão um espaço de ação na área que o afetava diretamente. No Sul do Brasil, a organização das comunidades assumiu um certo caráter de formação de um contrapeso à exclusão social num contexto de domínio oligárquico e de um Estado autoritário. A "ilha local de autodeterminação" ou Selbstverwaltung, na expressão de Krell (1994), teve no seu bojo a valorização do capital cultural e social, sempre sob a égide da religião, e o espírito de civismo dos colonos, através da sua participação na vida pública. Nesse sentido, Gertz (1991) tem razão em demonstrar que o estudo da Imigração está esvaziado de sentido quando não estabelece as relações entre história e política.

As escolas e as associações, enquanto expressões da face pública dos integrantes das comunidades, contribuíram para o processo de "recidadanização" e da elevação da auto-estima dos colonos. A "recidadanização" implicava em transformar os indivíduos em sujeitos sociais, isto é, fazer crer que cada um era capaz de dar prioridade em tudo o que fizesse para o bem do todo, o que reverteria, depois, para o bem de cada um. A responsabilização em torno das funções sociais e a aproximação das mulheres e dos jovens da vida da comunidade significaram a busca da fonte de articulação do poder local na família, baseadas nas relações do cotidiano. A família, a propriedade e a vida estariam, nesse sentido, mais seguras numa comunidade com um alto grau de capital social. As associações, ou comunidades cívicas, seriam, pois, 
expressão do grau de responsabilidade social e do nível de participação dos seus membros na construção do novo ente social identificado.

\section{A associação dos agricultores e a origem do cooperativismo rural}

Partindo das observações do cotidiano dos colonos, as lideranças da Igreja da Imigração perceberam que lhes faltava poder de competitividade e que, tampouco, muitos deles reuniam condições para remediar as suas necessidades mais prementes. O difícil acesso ao mercado e a pouca valorização dos produtos agrícolas eram elementos impeditivos de novas oportunidades, do acesso aos bens culturais e ao mercado formal. Era necessário, na verdadeira acepção da palavra, melhorar o seu nível material de vida e o seu bem-estar social para promover a sua elevação espiritual.

Católicos e evangélicos luteranos tiveram uma similar percepção do problema: para superar as suas limitações; os colonos deveriam unir-se em associações ou sociedades. Surgiu assim e desta apreensão, sob a liderança do padre Theodor Amstad, em 1900, a Associação Rio-grandense de Agricultores - Bauerverein -, detalhadamente estudada por Rambo (1988). Essa associação teve um caráter interconfessional e ocupou-se de questões centrais como: promoção da vida associativa, assistência social, formação de poupança e crédito agrícola, colonização e melhorias no universo da produção familiar.

A Associação Rio-grandense constituiu-se em uma organização social multifuncional, que conseguiu apreender a complexidade do universo dos pequenos agricultores. A busca de formas cooperadas para dar resposta aos desafios dos colonos, tanto no universo privado como no público era, portanto, a meta maior da Associação. As diferentes concepções em torno do desenvolvimento das atividades da Associação e as ingerências políticas do Estado fizeram com que a entidade fosse transformada em sindicato agrícola, em 1909, conforme os termos das leis de 1903 e de 1907, gozando, assim, da proteção oficial.

Para a maior parte das lideranças evangélico-luteranas, a transformação da Associação em sindicato permitiria uma inserção positiva 
na sociedade, dando-lhes poder de competitividade. $O$ freio ético-religioso não era fator impeditivo para a busca do êxito individual, uma vez que pela apreensão luterana da realidade os homens vivem a um só tempo em dois reinos: o espiritual e o material, onde o primeiro está ligado ao governo interior da pessoa, numa relação subjetiva com Deus e sem vínculo com os assuntos temporais, e o segundo orienta-se pela razão, pela tradição e pela autoridade constituída (SCHALLENBERGER, 2001). Decorre daí a compreensão de que a cooperação é uma forma de valorização da individualidade em vista dos resultados desejados. Por este entendimento, competição e cooperação não se excluem. Já os católicos, sustentados na perspectiva messiânica do Reino de Deus, fundamentavam o discurso da cooperação na solidariedade cristã, manifesta na família e na comunidade.

A vinculação da Associação de Agricultores ao sindicalismo oficial promoveu no associativismo cristão do Sul do Brasil caminhos de orientação diversa: de um lado, foi fundada, em 1912, da Sociedade União Popular para os Alemães Católicos do Rio Grande do Sul, com o objetivo de organizar e fortalecer as comunidades étnicas e confessionais; de outro, surgiu, através das Uniões Coloniais, congregadas a partir de 1929 em torno da Liga das Uniões Coloniais, uma estrutura sindical, adequada à legislação oficial, que se propôs a organização e a defesa dos interesses de classe; e, motivou o surgimento das organizações profissionais, como as cooperativas vitivinícolas e de laticínios, tendo em vista a organização e o melhoramento tecnológico da produção.

\section{Cooperativas de crédito e desenvolvimento comunitário}

A Sociedade União Popular, tendo como âncora as diretrizes lançadas por Roma para a defesa de uma ordem social cristã, buscou consolidar os seus núcleos comunitários através da "recidadanização" dos colonos, dando-lhes instrução cívica, promovendo a educação e a

${ }^{2}$ Informações em Deutsches Volksblatt, 23 jan. 1931. 
cultura étnica e católica e estimulando a poupança para que as diferentes comunidades étnicas pudessem desencadear um processo de desenvolvimento autônomo. No contexto do pós $1^{a}$ Guerra Mundial, a idéia de que a Igreja Católica era a única portadora de um modelo de sociedade justa e eqüitativa foi se plantando no seio das comunidades de forma tão intensa que as motivações cívicas enunciadas pelas lideranças comunitárias orientavam-se na direção de "unir todas as instituições católicas do mundo numa corrente, seguindo as mesmas diretrizes"2. As comunidades identificadas e autônomas passariam, assim, a estabelecer relações colaterais com suas pares e, ao mesmo tempo, manteriam vínculo em causa com um poder externo que thes assegurava orientação e conforto espiritual.

A autonomia das comunidades, num universo onde o dinheiro definia as possibilidades das pessoas, só poderia advir do aumento da geração de bens de valor e da poupança. A poupança interna apresentava-se como solução única para que as comunidades e seus membros não dependessem de poderes externos e se vissem livres da agiotagem. "O dinheiro governa o mundo, diz um ditado, se os agricultores tiverem dinheiro, terão o mundo inteiro". Compreendendo este aspecto central da dinâmica capitalista, Amstad e Siegfrid Kniest entendiam que o meio para garantir a autonomia das comunidades seria a implantação das caixas rurais.

O crédito agrícola apresentava-se como alternativa única para solucionar os problemas da dependência e do atraso dos colonos. Amstad entendia ser a dependência o maior dos males, por gerar submissão, exploração e agiotagem. A destinação de pequenas sobras individuais para um fundo de cooperação justificaria os valores incrementais que cada parte sozinha não conseguiria criar (RAMBO, 1988).

O cooperativismo de crédito, inaugurado em Nova Petrópolis RS, em 1902, por iniciativa de um grupo de colonos liderados pelo padre Amstad, surgiu como "comunidade de interesses para a auxílio mútuo", segundo definição de Englert (1926). Constitui-se, assim, a base para a formação de comunidades cívicas, espontâneas e voluntárias, reguladas por diretrizes estatutárias. O cooperativismo assim entendido, antes de promover a competição individual, criava competitividade comunitária. Representava uma resposta à decepção da coisa pública, mormente de- 
sacreditada pelas lideranças do associativismo cristão e diluída nas funções outorgadas pelo Estado à sociedade civil. Fomentava a estrutura horizontal das comunidades, apoiando iniciativas que dessem conta das múltiplas funções a serem desempenhadas nos campos religioso, assistencial, socioeconômico e político.

As caixas rurais, ou cooperativas de crédito, implantadas no Rio Grande do Sul e difundidas pelo Brasil, apoiaram-se nas experiências desenvolvidas na Alemanha e na Suíça, inspiradas no Sistema Raiffeisen. Friedrich W. Raiffeisen, admitindo o princípio natural da desigualdade dos homens, entendia que, pela solidariedade cristã, pela ajuda mútua e pela subsidiaridade, os mais ricos acabariam ajudando os mais pobres. Por outro lado, "se cada um depositar pequenas sobras dos frutos do trabalho, por menores que sejam, na soma grandes projetos podem ser financiados e podem reverter em benefício de cada um e de todos", acreditava (SCHALLENBERGER, 2001, p.26). O Sistema Raiffeisen não admitia a divisão dos lucros, que iam para um fundo de reserva para fomentar projetos sociais.

As caixas teriam que estar profundamente identificadas com as comunidades locais e a sua gestão deveria ser gratuita e limitada ao âmbito do seu funcionamento em cada localidade ou município. Não era admitida qualquer profissionalização ou sindicalização. Eram verdadeiras associações, ou comunidades de interesse mútuo, fundadas para promover a solidariedade e a formação moral dos seus associados.

"As caixas foram introduzidas para emprestar dinheiro ao colono para que ele não precisasse pagar juros altos aos bancos." "[...] ao invés de juros altos no banco, é mais seguro depositar nas caixas que investem o dinheiro em benefício de todos e todos saem ganhando. A caixa dá menos juros, mas mais proveito que o banco", sentenciava o órgão de divulgação oficial da Sociedade União Colonial. ${ }^{3}$

Entre as lideranças da Sociedade União Popular, as caixas ou cooperativas de crédito representavam um instrumento importante de solidificação do poder local e, por isso, foram concebidas e defendidas como organizações autônomas, sem vínculo com o Estado, representando uma espécie de instituto de autodefesa das comunidades.

\footnotetext{
${ }^{3}$ Informações em Skt Paulusblatt, Jun. 1923, p.1-2.
} 
A consolidação de comunidades cívicas para promover a autonomia das comunidades locais visava:

a) estimular a economia, para que os membros depositem o seu dinheiro em busca de rendimentos;

b) fomentar o crédito agrícola;

c) impedir o escoamento do dinheiro da terra e das comunidades;

d) combater a usura;

e) desenvolver um fundo de beneficência;

f) financiar novas frentes de colonização ${ }^{4}$

Identificadas como associações da Sociedade União Popular, as caixas rurais passaram a conviver com as cooperativas organizadas em forma de bancos populares que admitiam ajuda estatal, de conformidade com o Sistema Luzzatti, da Itália, e com o Decreto $\mathrm{N}^{\circ} 1.637$, de 5/ 1/1907. O controle estatal e a organização dos diferentes segmentos econômicos em sindicatos, levou a Sociedade União Popular à fundação de uma Central para as caixas, com a missão de promover o apoio mútuo, para alavancar o desenvolvimento das caixas locais e ter uma representação comum e uma orientação uniforme.. A fundação da Central contrariou as diretrizes traçadas por Amstad e os princípios do Sistema Raiffeisen. Sua constituição foi justificada, no entanto, em vista das demandas sociais e políticas. A Central deveria ser, na concepção dos seus idealizadores, um elo entre as caixas locais, sem priválas da sua independência. O discurso das lideranças católicas, a exemplo do presidente da Central, Gaston Englert, reforçava os princípios cristãos consagrados por Raiffeisen: "o Sistema Raiffeisen não é nada mais e nada menos do que o cooperativismo; pessoas se unem para desenvolver um trabalho de interesse comunitário, sem fins lucrativos, apenas de caridade cristã". ${ }^{5}$

Siegfrid Kniest, eminente professor paroquial e secretário da Sociedade União Popular, insistia muito na idéia da responsabilidade

"Informações em Deutsches Volksblatt, 18 Feb.1925.

s Informações em Deutsches Volksblatt, 22 abr. 1925. 
social como um dos pilares do cooperativismo. A responsabilidade ilimitada e o amor ao próximo apresentavam-se como exigências para dar consistência à comunidade cívica. Assim, prevalecendo o interesse comunitário ter-se-iam os meios suficientes para operar em casos extremos e poder-se-ia cumprir com o objetivo central das caixas, que era tornar os moradores das colônias economicamente auto-suficientes.

A Liga das Uniões Coloniais reconheceu as Caixas da União Popular, assim por ela denominadas, como importantes órgãos de fomento para incrementar o cooperativismo de produção. Por esta razão, estimulou o seu fortalecimento e a sua multiplicação. "Foi uma das criações mais interessantes ocorridas nas colônias", sustentavam as lideranças da Liga, tributando às caixas um poder de alavancagem econômica, social e cultural na produção social do espaço da colonização do Sul do Brasil ${ }^{6}$.

Até a edição do Decreto Federal 581, de 1 de agosto de 1938, que definiu nova estrutura para o cooperativismo, vinculando-o à orientação e à fiscalização dos órgãos públicos federais, haviam sido constituídas em torno de 50 cooperativas de crédito, que, somadas às de produção, fomentadas pela Liga das Uniões Coloniais, compuseram um quadro de 339 cooperativas no Rio Grande do Sul (OBERACKER JR, 1997). A trajetória do cooperativismo forjado a partir do associativismo cristão teve seu curso desviado pela instituição dos Consórcios Profissionais Cooperativos, pela vinculação do sistema de crédito rural às políticas de Estado, pela aplicação do Decreto n. ${ }^{\circ} 581 \mathrm{e}$ pelas políticas de repressão social, que inibiram a organização social (SCHALLENBERGER, 2001).

As caixas rurais, enquanto instrumentos de desenvolvimento comunitário e concebidas pelas lideranças do associativismo cristão, criaram um ambiente de interação e de interdependência entre as partes da comunidade. Na lógica da organização social concebida pela União Popular, o ideal comunitário prevalecia sobre o crescimento pessoal, o que não raras vezes criou inibições e resistências. O reflexo dessa concepção estampou-se na superação das condições individuais dos colonos pelo aparato comunitário. Eram visivelmente díspares os aportes infra-estruturais familiares dos comunitários. O tamanho das torres das

\footnotetext{
${ }^{6}$ Informações em Nachrichtenbblatt, Jun. 1931, p.12.
} 
igrejas não retratava de todo as condições de vida e as expectativas dos colonos. Apesar disso, a cultura da poupança não se restringiu às caixas de depósito e empréstimo, ou cooperativas de crédito. Ela enraizou-se na educação das crianças pelo estímulo dado à fundação de caixas escolares. Esteve presente nos grupos de jovens, que, além de exercitarem a responsabilidade em torno das funções públicas, buscavam um aporte financeiro para as suas atividades. Marcou a vida das entidades assistenciais, que, através de promoções diversas, formaram fundos emergenciais preventivos.

\section{No horizonte da investigação: cooperativismo e inovação tecnológica}

Embora as lideranças da Sociedade União Popular tivessem estimulado o cooperativismo de produção, foi no seio das Uniões Coloniais que ele ganhou expressão. Enquanto a Sociedade União Popular teve no cooperativismo o instrumento e a força necessárias para a organização de comunidades com poder de articulação suficiente para promover a sua autodeterminação, a Liga das Uniões Coloniais teve como horizonte a defesa dos interesses de classe, canalizados no sindicalismo e no cooperativismo. A cooperação foi entendida como capacitação dos indivíduos em vista dos resultados desejados e trazia no seu bojo a força da competição. Iluminado pela ética protestante, o caminho motivacional para a cooperação encontrou na competência e na tecnologia grau maior ou menor de satisfação.

A cooperação por si só não representaria razão suficiente para gerar competência e competitividade. A instrumentalização técnica do agricultor para o trabalho, o aumento da produtividade, a introdução de novas culturas e a qualificação e adequação dos produtos ao mercado apresentaram-se como possibilidades para o desenvolvimento do setor agrícola. A Liga das Uniões Coloniais estabeleceu, para tanto, uma aliança com o Estado, com o objetivo de incrementar escolas agrícolas e a organização de cooperativas de compra e venda. ${ }^{7} \mathrm{O}$ apoio

\footnotetext{
${ }^{7}$ Informações em Nachrichtenblatt, Jun. 1931.
} 
oficial do Estado, nem sempre tolerado, permitiu a presença de técnicos que estimularam as inovações nos diferentes setores da produção agrícola. Os agricultores passaram a se organizar em pequenas cooperativas especializadas de produção, o que possibilitou, sob a mediação da Liga e o incentivo do Estado, a introdução de novas culturas e de animas de raça, visando o aumento da produtividade, a melhoria genética e a adequação da produção às demandas do mercado. ${ }^{8} \mathrm{~A}$ introdução de novas pastagens, de novas técnicas de manejo dos animais e a organização de postos de monta contribuíram qualitativa e quantitativamente com a melhoria da produção pecuária, dando lugar de destaque à bacia leiteira e à matriz suína de produção de carne. A antiga matriz da produção de banha havia-se esgotado, em vista das restrições de mercado. A assistência técnica estimulou, também, o uso adequado e a recuperação do solo e o controle das pragas.

O desenvolvimento do cooperativismo, a melhoria das condições técnicas de produção e a organização do mercado para os produtos agrícolas incrementaram o agronegócio. Em torno das cooperativas de produção foram surgindo indústrias de transformação dos produtos, a exemplo dos abatedores, com extensão para os curtumes e as fábricas de calçados, dos laticínios, dos moinhos, das indústrias de fumo, para citar algumas representativas. A agroindústria cooperativa tornou-se importante fator de alavancagem da agricultura do Sul do Brasil, viabilizando as unidades familiares de produção e estimulando o desenvolvimento comunitário.

\footnotetext{
${ }^{8}$ Informações em Nachrichtenblatt, Ago./Set. 1931.
} 


\section{Referências}

BENATO, João V. $O A B C$ do cooperativismo. São Paulo: ICA, 1994.

ENGLERT, Gaston. Kassen und Volk. In: KATHOLIKENVERSAMMLUNG, 1926, Neu Hamburg. Anais... Neu Hamburg, 1926.

GERTZ, René E. O perigo alemão. Porto Alegre: Ed. da UFRGS, 1991.

KRELL, Andreas J. Associativismo municipal e proteção do meio ambiente na Alemanha. In: SEMINÁRIO INTERNACIONAL SOBRE EXPERIÊNCIAS COMUNITÁRIAS, 1994, Toledo. Não publicado.

KREUTZ, Lúcio. O professor paroquial: magistério e imigração alemã. Porto Alegre: Ed. da UFRGS, 1991.

MARTINS, G.I.V.; MARTINS, C.I.D. Desenvolvimento local: da teoria à prática. In: MARQUES, H. M.; RICCA, D.; FIGUEIREDO, G.P.; MARTÍN, J.C. Desenvolvimento local em Mato Grosso do Sul: reflexões e perspectivas. Campo Grande: UCDB, 2001.

OBERACKER JR, Carlos H. Vestígios suiços na história do Brasil. Revista de História, São Paulo, v.35, n.72, p.463-482, 1967.

PERROUX, François. L'économie du XX éme siècle. Paris: Presses Universitaires de France, 1962.

RAMBO, Arthur B. O associativismo teuto-brasileiro e os primórdios do cooperativismo no Brasil. Perspectiva econômica, São Leopoldo, v.23, n.6263, p.3-276, jul./dez. 1988.

SCHALLENBERGER, Erneldo. A integração do Prata no sistema colonial: colonialismo interno e missões jesuíticas do Guairá. Toledo: EdT, 1997.

SCHALLENBERGER, Erneldo. O associativismo cristão no Sul do Brasil. 2001. Tese (Doutorado) - Pontifícia Universidade Católica do Rio Grande do Sul, Porto Alegre. 


\section{Abstracts}

The present article appeals to the associativism practices, emphasising the system based on cooperatives, to conceive its incidences on the communities, on the local development and its contribuition to the process of technoligical inovation in the agricultural production universe.

Key words: associativism, local development, technoligical inovation. 